\title{
The Comparison of Propagation Model for Terrestrial Trunked Radio (TETRA)
}

\author{
Ayu Kartika R', Hani'ah M1, Nur Adi $\mathbf{S}^{1}$ \\ ${ }^{1}$ Politeknik Elektronika Negeri Surabaya \\ Kampus PENS, Jalan Raya ITS Sukolilo, Surabaya 60111 \\ Telp: (031) 594 7280; Fax: (031) 5946114 \\ Email: ayukartikaratnasari@gmail.com
}

\begin{abstract}
A system of digital radio Terrestrial Trunked Radio (TETRA) is designed for communication which need specialility, better privacy, better quality of audio with speed transmission data and access capacity to the internet and telephone network. TETRA system of TMO and DMO operation mode which has wide coverage and reliable than the interference so that the TETRA planning needs a propagation model which corresponding with environment. Therefore, this research compare a pathloss value of calculation of propagation model such as Free Space Loss, Wickson, Bacon, CEPT SE21, Ericsson (9999), ITU-R SM 2028 and Okumura Hata based on the environment are clutter urban, sub urban dan rural. The calculation of pathloss provide that Bacon propagation model is an corresponding model for DMO operation mode with a frequency of $380 \mathrm{MHz}$, height handhelds $1.5 \mathrm{~m}$ and $2 \mathrm{~m}$ with pathloss value of $76.82 \mathrm{~dB}$ at a distance of $100 \mathrm{~m}$ and $113.63 \mathrm{~dB}$ at a distance of $1 \mathrm{~km}$ while the $400 \mathrm{MHz}$ frequency pathloss value of $77.08 \mathrm{~dB}$ at a distance of $100 \mathrm{~m}$ and $113.6 \mathrm{~dB}$ at a distance of $1 \mathrm{~km}$. The propagation model which corresponding to the TMO operation mode with a frequency of $400 \mathrm{MHz}$ distance of $1 \mathrm{~km}$, the transmitter antenna height (hb) $30 \mathrm{~m}$ and receiver antenna height (hm) $1.5 \mathrm{~m}$ is a model of Ericsson (9999) on urban clutter with pathloss value of $96.4 \mathrm{~dB}$, the model ITU-R SM2028 in suburban clutter with a pathloss value of $101.13 \mathrm{~dB}$, and the model ITU-R SM2028 on rural clutter with pathloss value of $83.59 \mathrm{~dB}$.
\end{abstract}

Keywords: TETRA, propagation model, urban, suburban, rural

\section{Introduction}

Standar digital radio system ETSI of Terrestrial Trunked Radio (TETRA), the first version was pubblished in 1995 which had two directive transceiver specification, it was known as walkie talkie designed for professional user communication such as government agent, urgent official (police, fire fighter, ambulance), railway officer, official transportation and

Copyright (C) 2013 EMITTER International Journal of Engineering Technology - Published by EEPIS 
military [1]-[3]. Communication on TETRA had better privacy, better audio quality and speed increase in data transmission and capacity access to another network, such as internet and telephone network along with lower operational cost than GSM system [3]. Main operation mode of TETRA divided into 2, they are Trunked Mode Operation (TMO) and Direct Mode Operation (DMO). TETRA TMO as communication system used infrastructure network while TETRA DMO used to communicate in compound of TETRA terminal without using infrastructure network. Both are used handie talkie (HT) and mobile station (MS) as user equipment.

In order to obtain TETRA TMO and DMO that had wide area coverage and reliable against the interference so that a plan of TETRA needs propagation model which corresponding with environment. Propagation model is the basic element from communication network plan that very necessary to predict effective coverage area, analyzes the interference and cell parameter [4][5].

In communication network plan, a propagation model which used to pathloss calculation is needed. Pathloss is used to know the decrease of strength signal on receiver side. This parameter of strength signal is caused by attenuation at the receiver side is proportional to the distance of transmitter and receiver and the frequency used in communication. Besides, the pathloss is also influenced by environmental conditions. Therefore, this study discusses the pathloss calculation by using multiple propagation model suitable TETRA TMO and DMO for enviroment urban, sub-urban and rural.

\section{RELATED WORKS}

There are many research of TETRA for various application [3]-[4]. In Andrej Hrovat et al, research [4], entitled "Propagation Models for operation TETRA Direct Mode", discussed the mode propagation model TETRA DMO is applied to the DMO in space with a flat condition and the short distance of less than one kilometer. By comparing the propagation model of the free space loss (FSL), Bacon and CEPT SE21 with two models ray which passes through the wall using measurement field strength signal through a wall . The obtained results corresponding propagation model to estimate the TETRA DMO signal coverage for the two-ray model passes through the wall. Research done by Faihan D. Alotaibi et al [5] entitled "Terrestrial Trunked Radio (TETRA) Outdoor Large-Scale Received Signal Prediction Model in Riyadh Urban Areas", discussed the prediction propagation models for TETRA such as log distance provided measurement field strength signal at a frequency of $300 \mathrm{KHz}$ with results outdoor propagation model TETRA is the the exponent model with $n$ which has value $3 \pm 0.7$ for the regions of Saudi Arabia.

\section{ORIGINALITY}

The comparison with various calculation of propagation model e.g. FSL propagation model, Wickson, Bacon, CEPT SE21, Ericsson (9999), ITU-R SM 
2028 and Okumura Hata based on environment are urban, sub-urban and rural clutter shall be done for this research in order to obtain the appropriate propagation model with the TETRA TMO and DMO.

\section{DESIGN SYSTEM}

The calculation of pathloss rarameter TETRA, it utilizes uplink frequency $380 \mathrm{MHz}$ and downlink frequency $400 \mathrm{MHz}$. The DMO operation mode transmitter and receiver distance parameter it uses less than $1 \mathrm{~km}$ and four propagation models, namely Free space, Wickson, Bacon and CEPT SE21. The TMO operation mode with a distance of transmitter and receiver parameters 1-20 Km and propagation models, namely, Okumura Hata, ITU-R SM2028 and Ericsson (9999). Block diagram for the calculation of pathloss TETRA TMO and DMO operation modes are shown in Figure 1.

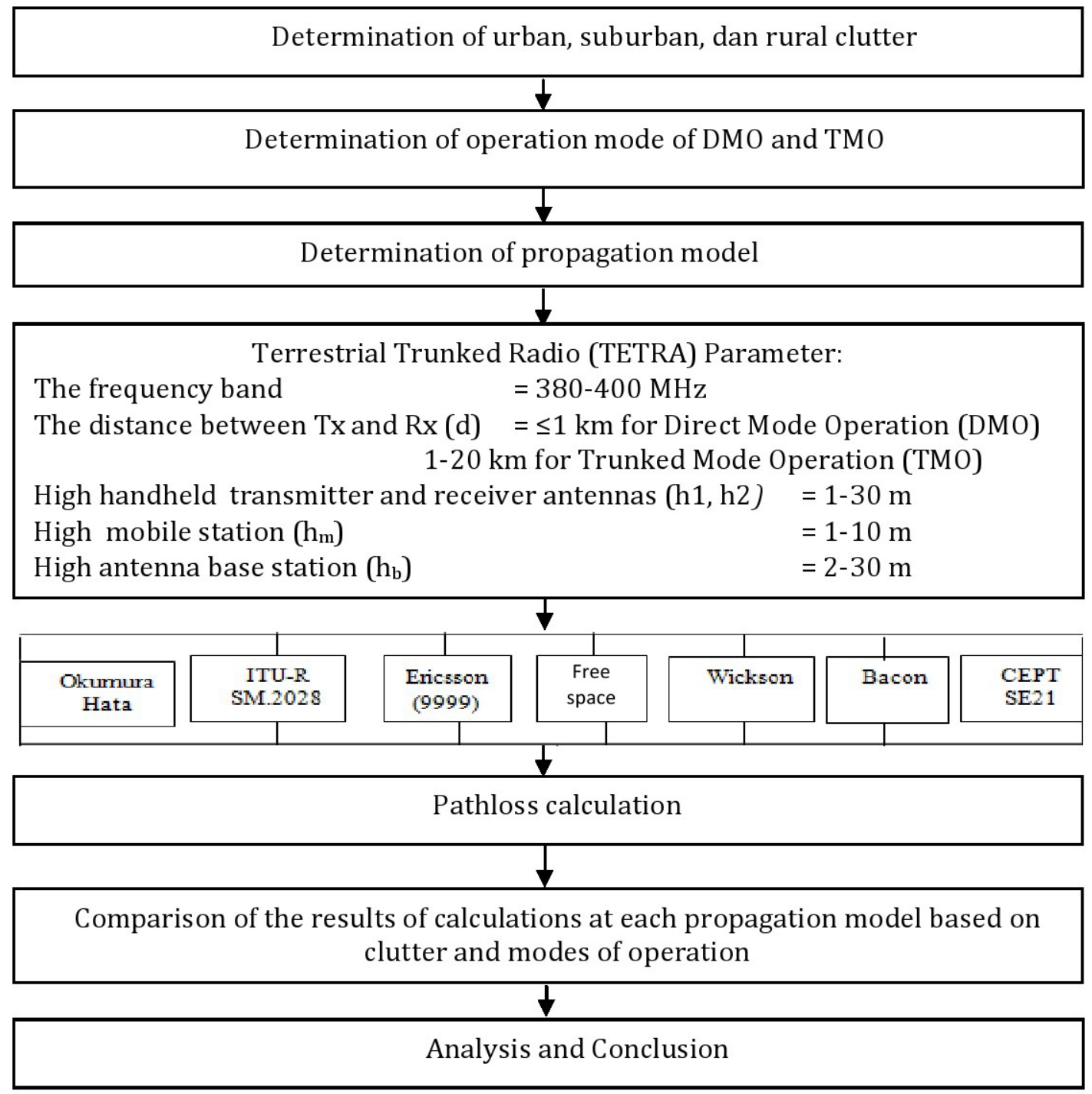

Figure 1. Blog of research diagram 
The calculation of the propagation model using the free space propagation model, Wickson, Bacon, CEPT SE21, Okumura Hata, ITU-R SM2028, Ericsson (9999) is shown as follows:

a. Free Space Model

Free space model [4] uses the frequency parameter (f) in $\mathrm{MHz}$ and the distance between the transmitter and receiver (d) in $\mathrm{km}$. The equation for the calculation of pathloss Free spaces (Lfs) is as in equation (1):

$$
\operatorname{Lfs}_{(\mathrm{dB})}=32,44+20 \log _{10} f+20 \log _{10} \mathrm{~d}
$$

b. Wickson Model

Wickson model is used as a comparison of the propagation model of FSL. The calculation of pathloss Wickson (Lw) as in equation (2):

$$
L w_{(d B)}=85,5+20 \log _{10} d+33 d
$$

c. Bacon Model

Bacon model [7] is used to clutter rural or open area . The parameters used in this model are the frequency (f) $\mathrm{MHz}$, the transmitter and receiver distance (d) $\mathrm{km}$, the percentage of the signal that is passed (p) \% , and the height handheld transmitter and receiver antennas (h1 ,h2) m. Pathloss calculation with Bacon model as in equation (3) with some parameters as in equation (4)-(10).

$$
\begin{aligned}
& \text { Lbacon }_{(d . B)}=10 \log _{10}(L 1+L 2) \\
& L 1_{(d \bar{B})}=32,4+20(f \cdot d)+10 \log _{10}\left(10^{[3-2 \log (100-p)]}+10^{-0,84}\right) \\
& L 2_{(d \bar{B})}=L m+L c \\
& L m_{(d \bar{B})}=120+40 \log _{10} d-20 \log _{10}(h 1 . h 2) \\
& L c_{(d B)} \quad=\mathrm{I}(0,01 \mathrm{p}) \sigma \quad \mathrm{p}>0,5 \\
& \sigma=\frac{L d}{2,3} \quad L d>0 \\
& =0 \quad \text { others } \\
& \operatorname{Ld}_{(\mathrm{dB})}=\mathrm{Im}-20 \log _{10} \text { (f. d) }-32,4 \\
& \sigma \min =2+0,1 f^{0,5} \\
& \text { if } \sigma<\sigma \min \text { so } \sigma=\sigma \mathrm{min}
\end{aligned}
$$


d. CEPT SE21 model

CEPT SE21 model in rural clutter [7] is by using the transmitter and receiver distance parameter (d) $\mathrm{km}$, the frequency (f) $\mathrm{MHz}$, and high handheld transmitter and receiver antennas (h1,h2) meters. CEPT SE21 pathloss calculations with parameter distance (d) between the transmitter and the receiver $\leq 0.04 \mathrm{~km}$ are equal to equation (1) free space loss (Lfs) as in equation (11):

$$
\text { Lcept } 1_{(\mathrm{dB})}=20 \log _{10} \mathrm{f}+20 \log _{10} \mathrm{~d}+32,44 \quad \mathrm{~d} \leq 0,04 \mathrm{~km}
$$

For the distance (d) at intervals of $0.04 \mathrm{~km}<\mathrm{d}<0.1$ miles then CEPT SE21 pathloss calculation as in equation (12) :

$$
\begin{aligned}
& \text { Lcept }_{(\mathrm{dB})}=69,6+26,2 \log _{10}-13,82 \log _{10}(\max (30 ; \mathrm{hmax})) \\
& +\left(44,9-6,55 \cdot \log _{10}(\max (30 ; \mathrm{hmax}))\right) \cdot \log _{10} \mathrm{~d}-\mathrm{a}(\mathrm{hmin})-\mathrm{b}(\mathrm{hmax}) \\
& \mathrm{d} \geq 0,1 \mathrm{~km}
\end{aligned}
$$

e. Okumura Hata Model

Okumura Hata model in the clutter of urban, suburban, and rural/open area [8] with the frequency parameter (f) $\mathrm{MHz}$, distance of the transmitter $(\mathrm{hb})$ and receiver $(\mathrm{hm}) \mathrm{m}$. For the calculation of pathloss with Okumura Hata model for urban obtained in equation (13) and sub-urban areas equation (16):

$$
\begin{aligned}
& \text { Lurban }(\mathrm{dB})=69,55+26,16 \log 10(\mathrm{f})-13,82 \log 10(\mathrm{hb}) \\
& \quad+(44,9-6,55 \log 10(\mathrm{hb})) \log 10(\mathrm{~d})-\mathrm{E} \\
& \text { LSuburban }(\mathrm{dB})=69,55+26,16 \log 10(\mathrm{f})-13,82 \log 10(\mathrm{hb}) \\
& +(44,9-6,55 \log 10(\mathrm{hb})) \log 10(\mathrm{~d})-2\left(\left(\log \left(\frac{\mathrm{f}}{2 \mathrm{n}}\right)\right)^{2}+5,4\right) \\
& \text { LRural(dB) }=69,55+26,16 \log 10(\mathrm{f})-13,82 \log 10(\mathrm{hb}) \\
& +(44,9-6,55 \log 10(\mathrm{hb})) \log 10(\mathrm{~d}) \\
& \begin{array}{c}
-4,78(\log 10(\mathrm{f}))^{2}+18,33 \log 10(\mathrm{f})+40,94 \\
\mathrm{E}(\mathrm{dB})=3,2(\log 10(11,7554 \mathrm{hm}))^{2}-4,97
\end{array}
\end{aligned}
$$

f. ITU - R Model SM2028

The ITU-R SM2028 model using frequency parameter (f) $\mathrm{MHz}$, base station antenna height (hb) meter and a mobile station (hm) meter with pathloss calculation for clutter urban, suburban, and rural in equations (17)-(19):

$$
\begin{aligned}
\mathrm{L}_{\mathrm{ITU} \text { urban }(\mathrm{dB})}= & 69,6+26,2 \log _{10}(\mathrm{f})-13,82 \log _{10}+(44,9 \\
- & \left.6,55 \log _{10}(\max (30, \mathrm{hb}))\right) \\
& \left.\log _{10}(\mathrm{~d})\right)^{\mathrm{a}}-\mathrm{a}(\mathrm{hm})-\mathrm{b}(\mathrm{hb})
\end{aligned}
$$




$$
\begin{aligned}
& \mathrm{L}_{\mathrm{ITU} \text { suburban }(\mathrm{dB})} \\
& =\mathrm{L}_{\mathrm{ITU} \text { urban }}-2 \cdot\left(\log _{10}\left(\frac{(\min (\max (150, \mathrm{f}), 2000))}{28}\right)\right)^{2}-5,4 \\
& \mathrm{~L}_{\mathrm{ITU} \text { rural }(\mathrm{dB})=} \\
& \mathrm{L}_{\mathrm{ITU} \text { urban }}-4,78 \cdot\left(\log _{10}(\min (\max (150, \mathrm{f}), 2000))\right. \\
& +18,33 \cdot \log _{10}(\min (\max (150, \mathrm{f}), 2000))-40,94
\end{aligned}
$$

g. Ericsson Propagation Model (9999)

The Eriksson (9999) model using the frequency parameter (f) $\mathrm{MHz}$, base station antenna height (hb) meter and a mobile station (hm) meter, and the parameters for each clutter $\left(\mathrm{a}_{0}, \mathrm{a}_{1}, \mathrm{a}_{2}, \mathrm{a}_{3}\right)$ for the calculation of pathloss in urban clutter, suburban, and rural as equation (20) [9]:

$$
\begin{aligned}
& \text { Lericsson }_{(\mathrm{dB})}=a_{0}+a_{1}, \log _{10}(d)+a_{2} \cdot \log _{10}(\mathrm{hb}) \\
& +a_{3}+\log _{10}(h b) \cdot \log _{10}(d)-3,2\left(\log _{10}(11,75 h m)\right)^{2}+g(f)
\end{aligned}
$$

The value of $g(f)$ as equation (21):

$$
g(f)_{(d B)}=44,49 \log _{10}(f)-4,78\left(\log _{10}(f)\right)^{2}
$$

\section{EXPERIMENT AND ANALYSIS} follows

Data processing for for the TETRA DMO and TMO could be explained as

\subsection{Analysis of pathloss for Direct Mode Operation ( DMO )}

Pathloss DMO calculation are influenced by change in distance and with frequency uplink $380 \mathrm{MHz}$ and downlink $400 \mathrm{Mhz}$ if handheld transmitter and receiver antennas $\mathrm{h} 1$ and $\mathrm{h} 2$ are $1.5 \mathrm{~m}$ and $2 \mathrm{~m}$. Comparison of four propagation models are Freespace, Wickson, Bacon, dan CEPT SE21. The result pathloss calculation curve can be seen at the figure 2 .

Pathloss at uplink frequency calculation result as function of distance and high of handheld transmitter antenna $\mathrm{h} 1$ is $1.5 \mathrm{~m}$ and high of of handheld transmitter antenna $\mathrm{h} 2$ is $2 \mathrm{~m}$ with Bacon propagation model will provide minimum pathloss $76.82 \mathrm{~dB}$ at $100 \mathrm{~m}$ near field and $113.4 \mathrm{~dB}$ at $1 \mathrm{~km}$ far field as shown in Figure 2a. Downlink frequency calculation result as function of distance and high of handheld transmitter antenna h1 is $1.5 \mathrm{~m}$ and high of of handheld transmitter antenna $\mathrm{h} 2$ is $2 \mathrm{~m}$ with Bacon propagation model will provide minimum pathloss $77.08 \mathrm{~dB}$ db at 100 m near field and $113.6 \mathrm{~dB}$ at 1 $\mathrm{km}$ far field as shown in Figure $2 \mathrm{~b}$. Bacon model has same pathloss value with Wickson model at $810 \mathrm{~m}$ that is equal to $110 \mathrm{~dB}$. From pathloss uplink dan downlink result can be expressed that more distance between transmitter and receiver then pathloss get bigger and higher antenna then pathloss gets smaller. 
Figure 2c and Figure 2d show Free Space propagation model having same value even though height of antennas are different. This is due to Free Space propagation model doesn not affect on the antenna height h1 and h2, this model is affected only frequency parameter and distance of transmitter and receiver. Downlink Frequency uses four propagation models Freespace, Wickson, Bacon, and CEPT SE21. Comparison result of Bacon and CEPT SE21 can produce pathloss value gets smaller if handheld transmitter antenna h1 and receiver $\mathrm{h} 2$ are higher. Whereas Freespace model and Wickson model resulted in fixed value since Wickson propagation model is only used at the fixed frequency $400 \mathrm{Mhz}$ and only affected by distance parameter from transmitter and receiver. In addition with that Free Space has smaller pathloss value then Wickson model.

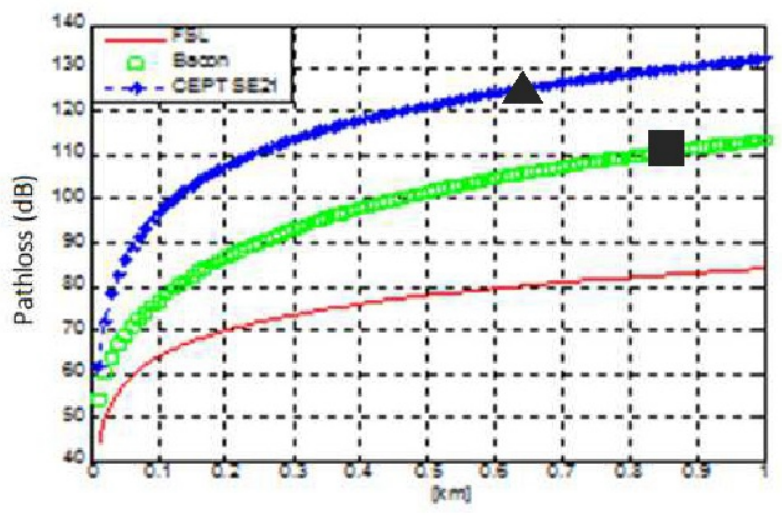

(a)

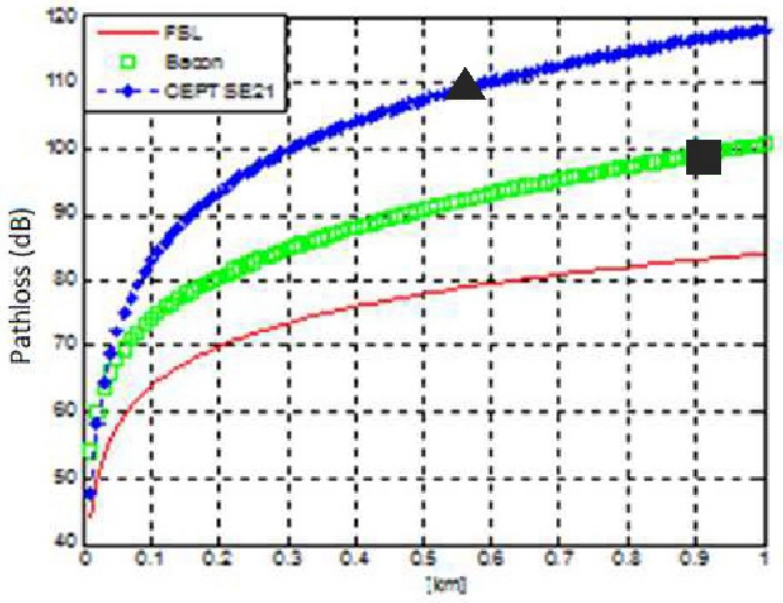

(c)

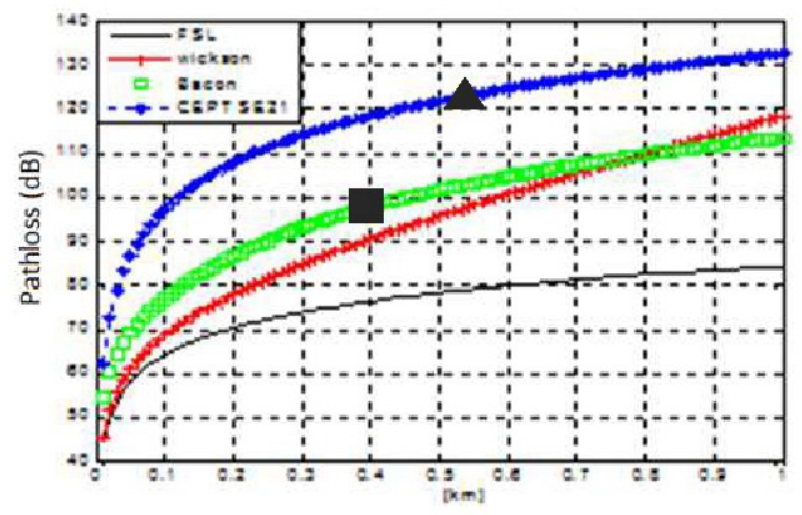

(b)

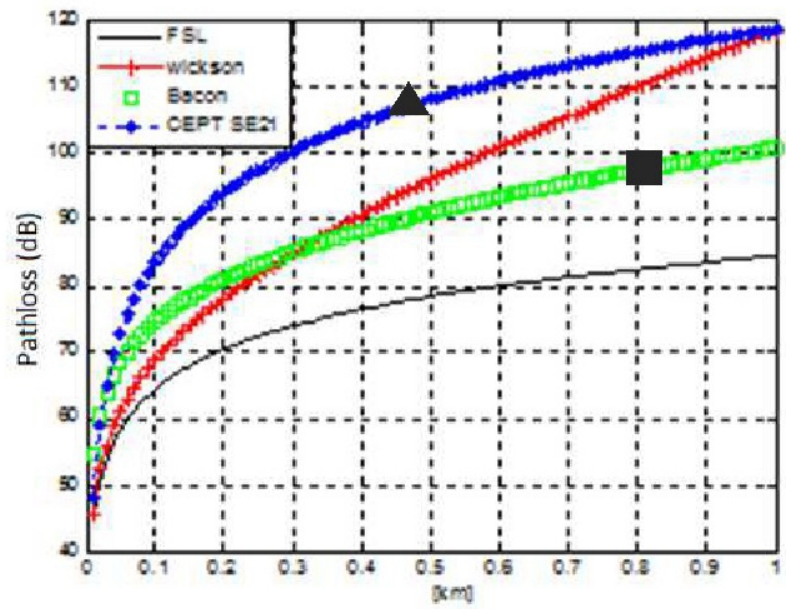

(d)

Figure 2. (a) Grafik pathloss uplink with height of antena $h_{1} 1,5 \mathrm{~m}$ dan $\mathrm{h}_{2} 2 \mathrm{~m}$., (b) Grafik pathloss downlink with height of antena $\mathrm{h}_{1} 1,5 \mathrm{~m}$ dan $\mathrm{h}_{2} 2 \mathrm{~m}$., (c) Grafik pathloss uplink with height of antena $\mathrm{h}_{1} 1,5 \mathrm{~m}$ dan $\mathrm{h}_{2} 10 \mathrm{~m}$., (d) Grafik pathloss downlink with height of antena h1 1,5m dan h2 10m. 


\subsection{Analysis of pathloss for Trunked Mode Operation ( TMO )}

Objective of this calculation is to determine impact of distance and clutter corresponding with pathloss TMO. Pathloss calculations with frequency $400 \mathrm{Mhz}$ and height of antenna $h_{m} 1,5 \mathrm{~m} \mathrm{~h}$ b $30 \mathrm{~m}$ curve is shown in Figure 3. Result in pathloss calculation for propagation model Okumura Hata, ITU-R SM2028 and Ericsson (9999) at the frequency $400 \mathrm{MHz}$ as function of distance and antenna height $h_{m} 1,5 \mathrm{~m}$ dan $h_{b} 30 \mathrm{~m}$ can be devide by

- in urban enviroment from three of propagation model are used Ericsson (9999) model result in pathloss value $96.4 \mathrm{~dB}$ at $1 \mathrm{~km}$ distance as seen in Figure 3a.

- In suburban enviroment from three of propagation model are used propagation model ITU-R SM2028 result in pathloss value 101,13 dB at $1 \mathrm{~km}$ distance as seen in Figure $3 \mathrm{~b}$.

- Rural enviroment from three of propagation model are used propagation model ITU-R SM2028 result in pathloss value 83,59 dB at $1 \mathrm{~km}$ distance as seen in Figure 3c.

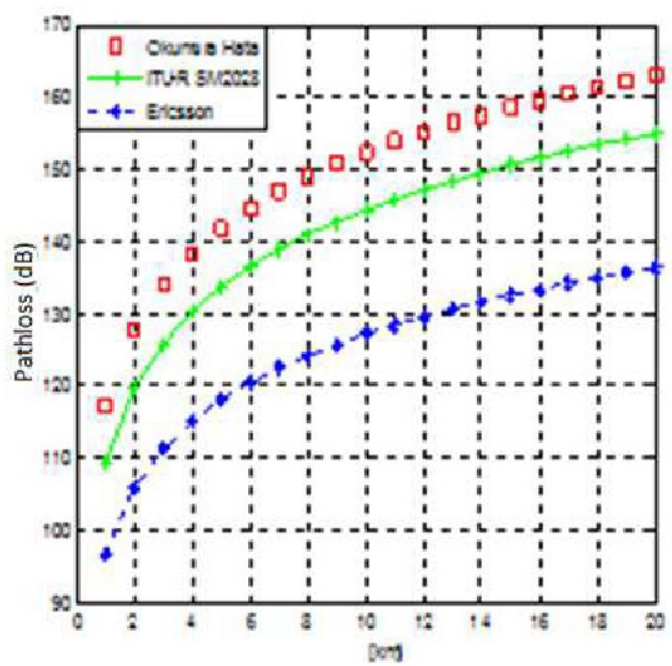

(a)

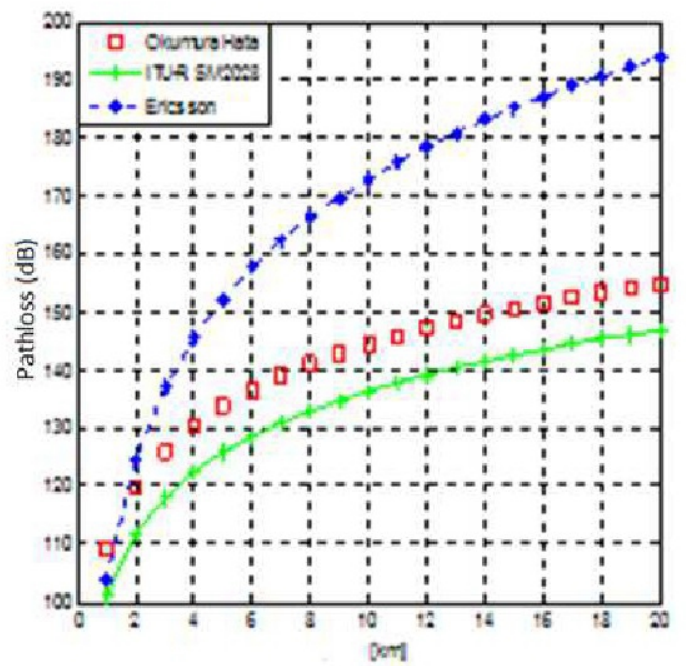

(b) 


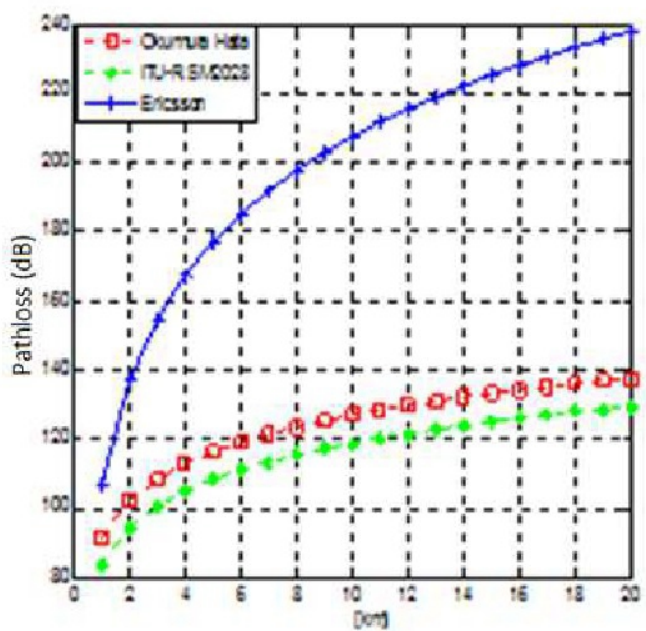

(c)

Figure 3. (a) Grafik pathloss urban on frequency $400 \mathrm{MHz}$ and height of antena $\mathrm{h}_{\mathrm{m}}$ $1,5 \mathrm{~m} \mathrm{~h}_{\mathrm{b}} 30 \mathrm{~m}$., (b) Grafik pathloss suburban on frequency $400 \mathrm{MHz}$ and height of antena $h_{m} 1,5 \mathrm{~m} \mathrm{~h}_{\mathrm{b}} 30 \mathrm{~m}$.,(c) Grafik pathloss rural on frequency $400 \mathrm{MHz}$ and height of antena $h_{m} 1,5 \mathrm{~m} \mathrm{~h}_{b} 30 \mathrm{~m}$.

\section{CONCLUSION}

Based on calculations using several pathloss propagation models in TETRA DMO and TMO it is obtained some conclusions as follows:

1. Propagation model corresponding to the operating mode Direct Mode Operation (DMO) is a model of Bacon. Freespace Model and Wickson not affect the height of the antenna so that the resulting pathloss value equal to the height of the antenna all conditions.

2. Operating mode Direct Mode Operation (DMO) with a frequency of 380 MHz uplink, handheld transmitter antenna height of $1.5 \mathrm{~m}$ and antenna handheld receiver height of $2 \mathrm{~m}$ Bacon model has a minimum pathloss of $76.82 \mathrm{~dB}$ at a distance of $100 \mathrm{~m}$, and $113.4 \mathrm{~dB}$ at a distance of $1 \mathrm{~km}$, while the results of the calculation of pathloss at downlink frequency of 400 $\mathrm{MHz}$, handheld transmitter antenna height of $1.5 \mathrm{~m}$ and $2 \mathrm{~m}$ receiver, Bacon propagation model produce minimum pathloss $77.08 \mathrm{~dB}$ at a distance of $100 \mathrm{~m}$ and $113.6 \mathrm{~dB}$ at a distance $1 \mathrm{~km}$. Bacon model pathloss experienced the same value with the Wickson model at a distance of 810 $m$ is equal to $110 \mathrm{~dB}$.

3. Model propagation Ericsson (9999) used according to the operating mode TMO on urban clutter and propagation model ITU-R SM2028 in suburban and rural clutter.

4. TMO on the operation mode of urban clutter on the uplink frequency of $400 \mathrm{MHz}$ with a distance function and an antenna height of hb $1.5 \mathrm{~m}$ and hm $30 \mathrm{~m}$, Ericsson model (9999) resulted in pathloss value of $96.4 \mathrm{~dB}$ at a distance of $1 \mathrm{~km}$. While suburban and rural area propagation model ITU-R SM2028 produce pathloss $83.59 \mathrm{~dB}$ and $101.13 \mathrm{~dB}$ at a distance of $1 \mathrm{~km}$. 


\section{Acknowledgements}

The writer would like to say gratitude to Allah SWT and without losing a sense of deep honour, great thank you for EMC Research Group.

\section{REFERENCES}

[1] ETSI, Terrestrial Trunked Radio (TETRA); User Requirement Specification TETRA Release 2; Part 8: Air - Ground - Air services, European Telecommunications Standards Institute (Eropa), ETSI TR 102 021-8 V1.1.1 (2003-09), 2003.

[2] ETSI, Terrestrial Trunked Radio (TETRA); Voice plus Data(V+D); Designers' guide; Part 3: Direct Mode Operation (DMO), European Telecommunications Standards Institute (Eropa), ETSI TR 102 300-3 V1.2.1 (2002-01), 2002.

[3] Syed Muhammad Naveed-Ul-Haq, Outdoor to Indoor Radio Wave Propagation For Wireless in Buildings Solutions, Master of Science Thesis Stockholm, Sweden, 2011.

[4] Andrej Hrovat, Tomaz Javornik, Gorazd Kandus, Propagation Models for TETRA Direct Mode Operation, WSEAS 8th WSEAS International Conference on APPLIED INFORMATICS AND COMMUNICATIONS (AIC'08) Rhodes, pp 8589, 2008.

[5] Faihan D. Alotaibi dan Adel A. Ali, Terrestrial Trunked Radio (TETRA) Outdoor Large - Scale Received Signal Prediction Model in Riyadh Urban Area, IEEE Wireless and Microwave Technology, pp 1-16, Clearwater, 2006. 